\title{
Descriptive analysis toward academic research experience by the Chinese undergraduate applicants to the graduate programs in the United States of America
}

\author{
Haocheng Lan ${ }^{1,}$, Xiaolong $\mathrm{Li}^{2,3, \mathrm{~b}, *}$ \\ ${ }^{1}$ Faculty of Social Science, University of Macau, Taipa, Macau, China; \\ ${ }^{2}$ School of Economics, Peking University, Beijing, 100876, China; \\ ${ }^{3}$ China National Health Development Research Center, NHFPC, Beijing, 100191, China. \\ alan423173@outlook.com, btell714@gmail.com
}

\begin{abstract}
As Chinese undergraduates travelling overseas to the United States of America for advanced degrees gains its ground among Chinese students, applicants to U.S. graduate schools are faced with admission criteria heading opposite directions. This paper presents a descriptive study over the academic performance of the Chinese applicants to the graduate programs in the United States, holding undergraduate research experience as the main measurement. Also, disciplinary difference across different majors on undergraduate research has been discussed in terms of pedagogical methods, and institutionalized facts behind the educational resources distribution.
\end{abstract}

Keywords: Overseas education; Graduate study; Pedagogical methods; Educational resources.

\section{Introduction}

Overseas education has been taken as a platform for the Chinese student to be better engaged in the international education atmosphere. The United States of America, as one of the destinations for Chinese overseas students, carries the fame for its eminent resources for the periodic time across university education. According to the statistics by the National Bureau of Statistics of China: in the year of 2015 alone, China, has sent 304,040 students overseas to the universities in the United States of America, making up 31.20\% of the total number for foreign students in US [1]. Among the mass of Chinese students to the United States in 2015, 120,331 of the overseas students were joining graduate programs. Chinese undergraduates' burgeoning interest in graduate programs in the United States has been the perseverance force for the growth of overseas education industry in China, keeping up with an at least $4 \%$ growth rate since the year of 2005. Prior studies on Chinese overseas education have turned out to be generally focusing on: 1. History of Chinese overseas education, 2. Qualitative analysis toward the rationales behind the popularization of overseas education in China, and 3. Quantitative research toward the overseas education industry in the United States and the correlated institutionalized policies in China.

Few researches have focused on the academic performance of the Chinese applicants for the US graduate programs, while the academic performance acts crucially for the graduate schools in examining their candidates' level of proficiency in the concerned fields of study. Undergraduate research can generally reveal students' level of integration in terms of major-related knowledge and practicing skills [2].

Undergraduate research has been at the core of interest for a number of programs funded and supported by varies of sources [3]. Undergraduates' experience of working for research-related programs functions as a cue for the prediction of their future performance [4]. Among the undergraduates in US universities, it is widely believed that having research experience written on their resume would improve their chances of getting admitted [4]. Prior research results have clarified that undergraduate research can be in assistance of uplifting undergraduates' proficiency in research-related knowledge and skills, increasing undergraduates' likelihood of getting accepted to advanced degrees, and establishing undergraduates' access to academic research $[3,5,6]$. This paper 
aims at bringing out a descriptive quantitative data analysis regarding the research experience of Chinese undergraduate applicants who have successfully applied to the US graduate schools.

\section{Method}

\subsection{Data collection and methods of measurement}

Aiming at discovering the features of the Chinese applicants in terms of academic experience, this study was carried out under the premise that research-related experience is positively correlated with the academic records by the undergraduate students. To gather data of the Chinese applicants to US graduate schools on a relatively large scale. Information of the successful applicants to US graduate schools was selected in accordance with pre- and post- investigations toward the undergraduates' documented information on the profile pages of LinkedIn. In the pre-investigation to the personal profiles, data of the undergraduates were examined for the listed information: 1. University of acceptance, 2. Year of acceptance and 3. Involvement of social and academic activities during the years of undergraduate study. With the three rules implemented in the pre-investigation of the Chinese undergraduates, the total population of successful Chinese applicants to the US graduate schools on LinkedIn $(=83.074)$ was filtered to settle the number of the sampled undergraduates $(\mathrm{N}=42,281)$. Together, they come from 30 universities out of the top 50 universities based on the evaluation by US news from 2013 to 2015 . After the data filtration in the pre-investigation, available records of the undergraduates were to be extracted of the following information: 1. Record(s) of research experience, 2. Record(s) of academic paper, and 3. Field(s) of study. As the application for admission to the graduate schools in the United States get initiated by the month of October each year, this study only had the sampled undergraduates' information at or before their junior year extracted. The personal profile on the webpage of Linkedin.com has by far shown no relative importance among the columns of personal information, blank columns on certain profiles have been counted as zero in the statistics for the study.

\subsection{Description of the sampled undergraduates}

After the data filtration process in the pre-investigation and data collection process in the post-investigation, 42,281 personal profiles of the Chinese undergraduates who have been admitted to thirty different graduate schools in the United States from 2013 to 2015 were sampled for the following study. Among the sampled undergraduates who have satisfied the implemented rules in the pre-investigation $(\mathrm{N}=42,281)$, Chinese applicants from 33 majors across the disciplines of sciences and technology, social sciences and humanities, and business have been included. 12,684 undergraduates from sciences and technology majors (MST), 19,027 undergraduates from social sciences and humanities majors (MSH), and 10,570 undergraduates from business majors (MB) got included. Of these Chinese applicants, 13,953 of them applied to the US graduate schools by the year of 2013 (33\%), 14,798 of them applied by the year of 2014 (35\%), and 13,890 of them applied by the year of $2015(32 \%)$.

\section{Results}

\subsection{Overall results of the statistics}

The number of Chinese undergraduates possess themselves with research experience at or before their third academic year was 9,917, 23.4 percent of the sampled subjects. Statistics toward the sampled undergraduates' research experiences were carried out in terms of the disciplines, majors of sciences and technology have taken up 67.59 percent of the total number, 6,703 Chinese applicants have experienced research-related program during their first three academic years. Besides the numbers for the sciences and technology majors, 1,810 undergraduates of social sciences and humanities, making up18.25 percent of the applicants with research experience, have joined undergraduate researches, while the number for the undergraduates of business majors is $1,403,14.15$ percent of the overall data. 
In Table 1, the data sets of Chinese applicants have been partitioned into 3 years: 2013, 2014, and 2015 under which the data of students joining in research-related programs are counted in accordance with the students' majors. To better assess the yearly change of Chinese applicants with undergraduate research experience admitted to US graduate schools across disciplines, the percentage of participation from 2013 to 2015 has been calculated to reflect the portion of the ones with research experience compared to the sum of Chinese applicants. Across disciplines, the percentage of students participating in undergraduate research has increased by 2.21 percent from the year of 2013 to 2015 . The disciplinary difference on participation to undergraduate research can be easily detected as the number of participants from MST $(6,703)$ has surpassed twice of the ones for students from MSH $(1,810)$, and $\mathrm{MB}(1,403)$ combined.

Table 1 Statistics of admitted Chinese undergraduates with experience of participating in research programs for their application to US graduate schools

\begin{tabular}{|c|c|c|c|c|c|}
\hline & & \multicolumn{4}{|c|}{ Year of $2013(n=13,953)$} \\
\hline \multirow[t]{2}{*}{ Variables } & \multirow[t]{2}{*}{ Overal $(n=42,281)$} & \multicolumn{4}{|c|}{ Disciplines } \\
\hline & & MST & MSH & MB & Overall \\
\hline 1. Number of participating students & 9,917 & 2,012 & 557 & 443 & 3,012 \\
\hline 2. Total number of applicants & 42,281 & 4,105 & 6,289 & 3,471 & 13,865 \\
\hline \multirow[t]{2}{*}{ 3. Percentage of participating students } & $23.40 \%$ & $49.01 \%$ & $8.86 \%$ & $12.76 \%$ & $23.33 \%$ \\
\hline & & \multicolumn{4}{|c|}{ Year of $2014(n=14,798)$} \\
\hline \multirow[t]{2}{*}{ Variables } & Overall $(\mathrm{n}=42,281)$ & \multicolumn{4}{|c|}{ Disciplines } \\
\hline & & MST & MSH & MB & Overall \\
\hline 1. Number of participating students & 9,917 & 2346 & 634 & 481 & 3,461 \\
\hline 2. Total number of applicants & 42,281 & 4,520 & 6,479 & 3,688 & 14,687 \\
\hline \multirow[t]{2}{*}{ 3. Percentage of participating students } & $23.40 \%$ & $51.90 \%$ & $9.79 \%$ & $13.04 \%$ & $23.58 \%$ \\
\hline & & \multicolumn{4}{|c|}{ Year of $2015(n=13,890)$} \\
\hline \multirow[t]{2}{*}{ Variables } & Overall $(\mathrm{n}=42,281)$ & \multicolumn{4}{|c|}{ Disciplines } \\
\hline & & MST & MSH & MB & Overall \\
\hline 1. Number of participating students & 9,917 & 2,345 & 619 & 480 & 3,444 \\
\hline 2. Total number of applicants & 42,281 & 4,059 & 6,235 & 3,435 & 13,729 \\
\hline 3. Percentage of participating students & $23.40 \%$ & $57.77 \%$ & $9.92 \%$ & $13.97 \%$ & $25.08 \%$ \\
\hline \multicolumn{6}{|c|}{$\begin{array}{c}\text { Note: 1. Blank entries in the concerned columns of personal profile pages have not been included in the } \\
\text { statistics }\end{array}$} \\
\hline 2. MST: majors of sciences and & $\begin{array}{l}\text { nnology; MSH: majors } \\
\text { majors of business }\end{array}$ & f social sc & ences and & humaniti & es; MB: \\
\hline
\end{tabular}


The rate of change in students participating in undergraduate research has also manifested the difference between disciplines. Compared to the change in students from MSH and MB, an 8 percent growth in the number of MST students with research-related experience appears to be rampant.

Table 2 Statistics of times Chinese undergraduates participating in research-related programs for their application to graduate schools in the United States

\begin{tabular}{|c|c|c|c|c|c|}
\hline \multirow[b]{3}{*}{ Variables } & \multirow[b]{3}{*}{$\begin{array}{c}\text { Overall } \\
(n=42,281)\end{array}$} & \multicolumn{4}{|c|}{ Disciplines } \\
\hline & & \multirow[b]{2}{*}{$\begin{array}{c}2013 \\
(n=4105)\end{array}$} & \multicolumn{2}{|c|}{ MST } & \multirow[b]{2}{*}{$\begin{array}{l}\text { Overall } \\
\text { average }\end{array}$} \\
\hline & & & $\begin{array}{c}2014 \\
(n=4520)\end{array}$ & $\begin{array}{c}2015 \\
(\mathrm{n}=4059)\end{array}$ & \\
\hline 1. Times of participating & 25,381 & 3,243 & 3,661 & 3,369 & 3,424 \\
\hline $\begin{array}{l}\text { 2. Times of participating per } \\
\text { participants }\end{array}$ & 2.56 & 1.61 & 1.56 & 1.43 & 1.53 \\
\hline \multirow[t]{2}{*}{$\begin{array}{l}\text { 3. Times of participating per } \\
100 \text { students }\end{array}$} & 60 & 79 & 81 & 83 & 81 \\
\hline & & & \multicolumn{2}{|c|}{$\mathrm{MSH}$} & \\
\hline Variables & $\begin{array}{c}\text { Overall } \\
(\mathrm{n}=42,281)\end{array}$ & $\begin{array}{c}2013 \\
(n=6289)\end{array}$ & $\begin{array}{c}2014 \\
(\mathrm{n}=6479)\end{array}$ & $\begin{array}{c}2015 \\
(\mathrm{n}=6235)\end{array}$ & $\begin{array}{l}\text { Overall } \\
\text { average }\end{array}$ \\
\hline 1. Times of participating & 25,381 & 2,704 & 3,045 & 2,945 & 2,898 \\
\hline $\begin{array}{l}\text { 2. Times of participating per } \\
\text { participants }\end{array}$ & 2.56 & 4.85 & 4.80 & 4.76 & 4.80 \\
\hline \multirow[t]{2}{*}{$\begin{array}{l}\text { 3. Times of participating per } \\
100 \text { students }\end{array}$} & 60 & 40 & 47 & 47 & 46 \\
\hline & & & \multicolumn{2}{|c|}{$\mathrm{MB}$} & \\
\hline Variables & $\begin{array}{c}\text { Overall } \\
(\mathrm{n}=42,281)\end{array}$ & $\begin{array}{c}2013 \\
(\mathrm{n}=3471)\end{array}$ & $\begin{array}{c}2014 \\
(\mathrm{n}=3688)\end{array}$ & $\begin{array}{c}2015 \\
(\mathrm{n}=3411)\end{array}$ & $\begin{array}{l}\text { Overall } \\
\text { average }\end{array}$ \\
\hline 1. Times of participating & 25,381 & 2,013 & 2,250 & 2,151 & 2,138 \\
\hline $\begin{array}{l}\text { 2. Times of participating per } \\
\text { participants }\end{array}$ & 2.56 & 4.54 & 4.68 & 4.49 & 4.57 \\
\hline $\begin{array}{l}\text { 3. Times of participating per } \\
100 \text { students }\end{array}$ & 60 & 58 & 61 & 63 & 61 \\
\hline \multicolumn{6}{|c|}{$\begin{array}{c}\text { Note: } 1 \text {. Blank entries in the concerned columns of personal profile pages have not been included in the } \\
\text { statistics }\end{array}$} \\
\hline
\end{tabular}

In Table 2, times of sampled undergraduates participating in research-related programs are counted based on the disciplines of their majors. Overall, counting of the data has shown that undergraduates from MST majors joined in more undergraduate research programs than students from other disciplines. However, undergraduate researchers from MSH and MB participated in more research on average than science students. The rate of MST students participating in undergraduate research verge on the whole of the total number, up to 81 percent of the students from MST have similar experience. 
When it comes to the matter of research participating time for the undergraduate researchers, MSH students who have ever joined research-related activities have engaged in more times of it. For each MSH researchers, on average, one has joined in 4.80 times of researches. Per 100 students, Chinese applicants to MSH have joined in 81 times of research-related activities. For the ones applying to $\mathrm{MSH}$, this number would become 46 times, and when it comes to the MB, it is 61 times for every undergraduate participants in research-related projects.

Table 3 Statistics of the Chinese undergraduates writing academic papers as an outcome for the research-related programs for their application to graduate schools in the United States

\begin{tabular}{|c|c|c|c|c|c|}
\hline \multirow[b]{3}{*}{ Variables } & \multirow[b]{3}{*}{$\begin{array}{c}\text { Overall } \\
(\mathrm{n}=42,281)\end{array}$} & \multicolumn{4}{|c|}{ Disciplines } \\
\hline & & \multicolumn{3}{|c|}{ MST } & \multirow[b]{2}{*}{$\begin{array}{l}\text { Overall } \\
\text { average }\end{array}$} \\
\hline & & $\begin{array}{c}2013 \\
(n=4105)\end{array}$ & $\begin{array}{c}2014 \\
(n=4520)\end{array}$ & $\begin{array}{c}2015 \\
(n=4059)\end{array}$ & \\
\hline 1. Times of participating & 25,378 & 3243 & 3661 & 3369 & 3,424 \\
\hline 2. No. of academic papers & 17854 & 1998 & 2368 & 2174 & 2180 \\
\hline 3. Papers per participating time & 0.73 & 0.62 & 0.65 & 0.65 & 0.64 \\
\hline \multirow[t]{2}{*}{$\begin{array}{l}\text { 4. Papers per } 100 \text { Chinese } \\
\text { applicants }\end{array}$} & 42 & 49 & 52 & 54 & 52 \\
\hline & & & \multicolumn{2}{|c|}{ MSH } & \\
\hline Variables & $\begin{array}{c}\text { Overall } \\
(\mathrm{n}=42,281)\end{array}$ & $\begin{array}{c}2013 \\
(n=6289)\end{array}$ & $\begin{array}{c}2014 \\
(\mathrm{n}=6479)\end{array}$ & $\begin{array}{c}2015 \\
(\mathrm{n}=6235)\end{array}$ & $\begin{array}{l}\text { Overall } \\
\text { average }\end{array}$ \\
\hline 1. Times of participating & 25,378 & 2704 & 3045 & 2945 & 2,898 \\
\hline 2. No. of academic papers & 17854 & 1955 & 2524 & 2456 & 2312 \\
\hline 3. Papers per participating time & 0.73 & 0.72 & 0.83 & 0.83 & 0.80 \\
\hline \multirow[t]{2}{*}{$\begin{array}{l}\text { 4. Papers per } 100 \text { Chinese } \\
\text { applicants }\end{array}$} & 42 & 31 & 39 & 39 & 36 \\
\hline & & & \multicolumn{2}{|c|}{ MB } & \\
\hline Variables & $\begin{array}{c}\text { Overall } \\
(n=42,281)\end{array}$ & $\begin{array}{c}2013 \\
(\mathrm{n}=3471)\end{array}$ & $\begin{array}{c}2014 \\
(n=3688)\end{array}$ & $\begin{array}{c}2015 \\
(n=3411)\end{array}$ & $\begin{array}{l}\text { Overall } \\
\text { average }\end{array}$ \\
\hline 1. Times of participating & 25,378 & 2013 & 2250 & 2151 & 2,138 \\
\hline 2. No. of academic papers & 17854 & 1308 & 1598 & 1473 & 1460 \\
\hline 3. Papers per participating time & 0.73 & 0.65 & 0.71 & 0.68 & 0.68 \\
\hline $\begin{array}{l}\text { 4. Papers per } 100 \text { Chinese } \\
\text { applicants }\end{array}$ & 42 & 38 & 43 & 43 & 41 \\
\hline
\end{tabular}

Note: 1. Blank entries in the concerned columns of personal profile pages have not been included in the statistics

2. MST: majors of sciences and technology; MSH: majors of social sciences and humanities; MB: majors of business

Academic paper is taken as one of the outcomes of undergraduate research. Table 3 is set out to compare the academic outcomes by the sampled undergraduates in terms of disciplinary difference and annual statistics. Among the applicants with research-related experience, students from MSH have written more academic papers than the undergraduates from the other two disciplines. On 
average, MSH researchers write 0.80 paper per program. MB research participants have had 0.68 academic papers for each of their activities. MST students write 0.64 paper for every research.

\subsection{Sampling distribution of the universities accepting the sampled Chinese applicants}

The 42,281 sampled Chinese undergraduate applicants from the year of 2013 to 2015 got admitted to 30 different universities in total. In Figure 1, the number of academic papers per 100 students by the undergraduates admitted by the 30 universities in the United States is used as a measurement of the data set. In Figure 1, y-axis represents the distribution frequency of the data points while $\mathrm{x}$-axis stands for the number of papers per 100 students. According the carried out calculation, mean for this data set is 48.61 academic papers per 100 students with a standard deviance of 19.12. Shape of the sampling distribution graph for the data set shows as Figure 1.

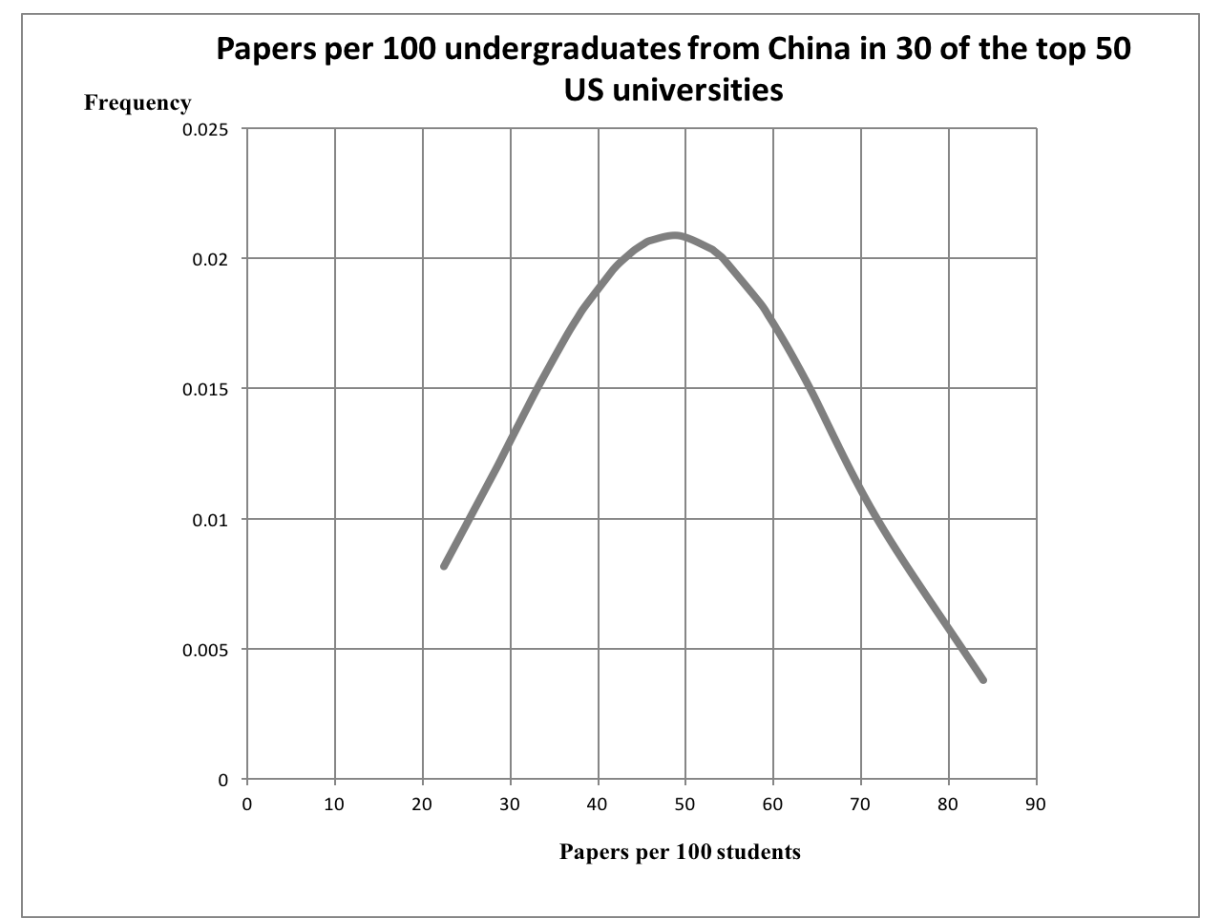

Figure 1 Sampling distribution of papers per 100 Chinese applicants admitted by U.S. graduate schools

\section{Conclusion and Discussion}

While the correlation between the experience of doing undergraduate research and the admission from the targeted graduate schools remains to be discovered, disciplinary and specific skills for further study and critical thinking are deemed to be crucial criteria for the admission to graduate schools in the United States [4]. In order to fulfill the requisite needs of proving their integrated skills and elaborative thinking, applicants for the graduate schools can turn to one of the applicable solutions, undergraduate research. The statistical result of the Chinese applicants of the recent years have reflected the increasing recognition toward undergraduate research. However, the saying above has only discussed the feature of admission criteria for US graduate schools in general, whereas the level of emphasis on skills and thinking could be different on disciplinary basis. The difference among majors would be inevitably overlooked if we only refer to the general growth rate of undergraduates doing research. The observed disciplinary difference in undergraduates participating in research-related programs can be inferred from the gaps of statistical result of participation rate between disciplines. MST has got more of the students participating in undergraduate research on percentage than any of the MSH and MB. Reasons behind this participation difference come from the discrepancy in pedagogical instruments of varied majors [7]. Multi-institutional researches has found that undergraduates from science majors participating in research-related programs receives positive responses in their practical skill enhancement: interpretation of data, formulation of hypothesis 
toward research gains, and initiative in communication [8]. Another part of the rationale behind the high participation rate for the students of science majors could be attributed to the fact that undergraduate researchers from the science and technology disciplines are more likely to pursue advanced degrees [9].

As the prior assessment toward the undergraduate research of social science and humanities found that it is the subsequent academic conference rather than the process of research more beneficial to the application of the undergraduates [10]. Unlike the other two disciplines, business majors are more focused on the studies of prior cases in the forms of course-based activities and projects conducted across faculties. Different instructional methods for the MSH, and MB offered the students of the particular majors comparatively more exposure to the research-related activities, making it probable for them to be involved in more research-related programs. The results of this study shown in Table 1-2 appear to be consistent with the words from the mentioned studies as the statistical numbers has shown that research participants from MSH and MB appear in more times of undergraduate research than the research participants of MST.

As the empirical research on the quality of undergraduate academic papers states: unlike the US schools, quantitative evaluation toward educational accomplishment in Chinese schools largely holds practical outcomes at the core rather than the subjects' engagement to the process of doing research $[11,12]$. Rationales behind this stated fact could be concluded that: (1) the instructional methods included in the university curriculums for the two countries are different. While the critical thinking and fundamental skills are valued in the American universities, academic grades as one of the outcomes of the academic studies tend to be more crucial among Chinese curricular goals. (2) Chinese universities' instructional methods are constrained by the restricted academic resources. According to the 2014 statistics by the National Bureau of Statistics of China, the number of undergraduates on campus for the year of 2015 has been calculated in accordance with the reported number of students on campus in 2014, students graduated in 2014 , and the proposed number of students admitted in 2014. As the result has shown out: by 2015 , there are 26.10 million undergraduates in China, compared to the number of 2014 (25.90 million), we will be seeing a 7 percent growth. (National Bureau of Statistics of China, 2014) Nevertheless, the resources of education, mainly determined by the number of universities has been continuously set back from growing. Compared to the number of Chinese universities and colleges in 2014, there are only 24 newly set up universities and colleges by 2015, a 0.9 percent of growth (National Bureau of Statistics of China, 2015). To adopt the American style of educational instruments, the resources for education in China require further growth.

Number of academic paper has been taken as one of the measurement to work out the sampling distribution of academic requirement behind the admission criteria to the graduate schools in the United States. The graduate schools included in the study are the top 30 schools in number when the data of the 2013-to-2015 Chinese applicants are collected from LinkedIn. The shape of the figure in Figure 1 appears to be close to the ones for normal distribution. As the scale of this study on the number of sampled subjects $(42,281)$ has been shown to be relatively large compared to the total number of Chinese undergraduates admitted to US graduate schools. The effect shown in the sampling distribution figure could be equivalent to a survey carried out in a random sampling. According to the central limit theorem of sampling distribution, random sampling with a large enough sample size, the sampling distribution is approximately a normal distribution. The result of Figure 1, if implemented by more data from more US graduate schools, would be more comprehensive in measuring the academic requirement, reflected by the experience of participating in undergraduate research. Compared to the result carried out in one of the key universities in Beijing, China, the percentage of undergraduates at or reaching the third academic year in school from the concerned university having participated in research-related activities is inferred to be $18.60 \%$, with 19 academic papers per 100 students as the outcome from these researches from the same university $(\mathrm{Li}, 2015)$. Referring to table 2 of sampling distribution under the sample size of $30(n=30)$, and putting this number into comparison with the result of this study toward the Chinese applicants to US graduate schools, the result of academic papers per 100 students in this Chinese university falls at the last 
$15.39 \%$ in number. Across disciplines, Chinese undergraduates, restricted by the limited educational resources and different instructional methods, participate in less research-related activities than the students in the United States. Despite this fact, the statistical results of this study have reflected the fact that the Chinese undergraduates with the goals of applying to the US graduate schools have participated in research-related programs in higher percentage, in more times of activities, and ended up in more academic outcomes, mirrored by the number of academic papers.

\section{References}

[1] National Bureau of Statistics of China. (2015). 2015 statistics of overseas students to the United States of America joining bachelor and advanced degree study.

[2] Bauer, K. W., \& Bennett, J. S. (2003). Alumni perceptions used to assess undergraduate research experience. Journal of Higher Education, 74(74), 210-230.

[3] Seymour, E., Hunter, A., Laursen, S. L., \& Deantoni, T. (2004). Establishing the benefits of research experiences for undergraduates in the sciences: first findings from a three-year study. Science Education, 88(4), 493-534.

[4] Craney, C., \& Groot, R. D. (2011). Cross-discipline perceptions of the undergraduate research experience. Journal of Higher Education, 82(1), 92-113.

[5] Frantz, K. J., Dehaan, R. L., Demetrikopoulos, M. K., \& Carruth, L. L. (2006). Routes to research for novice undergraduate neuroscientists. Cbe Life Sciences Education, 5(2), 175-87.

[6] Hunter, A., Laursen, S. L., \& Seymour, E. (2007). Becoming a scientist: the role of undergraduate research in students' cognitive, personal, and professional development. Science Education, 91 (1), págs. 36-74.

[7] Scott R. Steele. (2008). Web-based surveys facilitate undergraduate research and knowledge. Journal of Economic Education, 39(1), 41-49.

[8] Kardash, C. (2000). Evaluation of an undergraduate research experience: perceptions of undergraduate interns and their faculty mentors. Journal of Educational Psychology, 92(1), 191-201.

[9] Hathaway, R. S., Nagda, B. A., \& Gregerman, S. R. (2001). The relationship of undergraduate research participation to graduate and professional education pursuit: an empirical study. Journal of College Student Development, 43(5), 614-631.

[10] Nnadozie, E., Ishiyama, J., \& Chon, J. (2000). Undergraduate research internships and graduate school success. Journal of College Student Development, 42(2), 29.

[11]Xu, C. (2013). Comparative study on China-US' school evaluation: organization, standard and practice. East China Normal University.

[12]Mao, D. (2015). Performance funding policy for higher education in u. s. a: a literature review. Education Research Monthly.

[13] National Bureau of Statistics of China. (2014). 2014 Statistics of undergraduates enrolled in universities.

[14] National Bureau of Statistics of China. (2015). 2015 Statistics of newly set-up universities.

[15]Li, X. (2015). Undergraduate research participation and its influences on Student development: an empirical study in a Chinese University. Education Research Monthly. 